\title{
Pênis de Comprimento Reduzido em Idade Pré-Puberal: Avaliação Inicial e Seguimento
}

\section{RESUMO}

São poucos os dados disponiveis sobre a avaliação e evolução dos pacientes com pênis morfologicamente normal, mas de comprimento reduzido para a idade. Neste estudo, foram avaliados 8 meninos que se apresentaram com desenvolvimento sexual pré-puberal, com pênis de comprimento um ou dois desvios-padrão abaixo da média e sem evidências de endocrinopatia. Em 6 casos os pacientes foram seguidos por 1 ano e 2 meses a 8 anos e 7 meses, dois deles tendo recebido curso(s) de testosterona. Na última avaliação todos os pacientes apresentavam desenvolvimento puberal, três deles com pênis na faixa normal para a idade e três apresentando comprimento peniano um desvio-padrão abaixo da média. A evolução clínica benigna aqui observada favorece a adoção de conduta expectante em alguns casos, individualizando a necessidade de intervenção terapêutica com testosterona. (Arq Bras Endocrinol Metab 2000;44/5: 413-416)

Unitermos: Pênis pequeno; Micropênis; Puberdade normal; Testosterona

\section{artigo original}

\author{
Tiago Schuch \\ Ana Paula Weidlich \\ Miriam da C. Olipeira
}

\begin{abstract}
There is scarcely available data about the evaluation and evolution of patients with morphologically normal penis, but with reduced length according to the age. In this study, 8 boys were evaluated, with prepubertal development, presenting penis length one or two standarddeviation bellow average and with no evidence of endocrine pathology. In 6 cases the patients were observed for 1 year and 2 months to 8 years and 7 months. Two of them were submitted to testosterone treatment. In the last evaluation, all patients presented pubertal development, three of them with normal penis length for the age, and three of them presenting penis length one standard deviation bellow the average. The benign clinical evolution observed favors the adoption of expectant behavior in some of these cases, while testosterone treatment should be applied only in special ones. (Arq Bras Endocrinol Metab 2000;44/5: 413-416)
\end{abstract}

Keywords: Penis length; Micropenis; Normal puberty; Testosterone

$\mathrm{E}$ M HUMANOS, O CRESCIMENTO DO PÊNIS OCORRE em quatro fases: precocemente na gestação, resultando num comprimento médio no recém-nascido de $3,5 \mathrm{~cm}$; do nascimento até os dois anos, quando ocorre um acréscimo de $1,5 \mathrm{~cm}$; dos dois aos 11 anos, novo acréscimo de $1,5 \mathrm{~cm}$; e na puberdade, quando atinge o tamanho adulto (1). $O$ mecanismo de cessação do crescimento não está claro (2).

O diagnóstico diferencial de um pênis pequeno na infância, morfologicamente normal, inclui o pênis oculto, o micropênis e um pênis de comprimento reduzido para a idade. Pênis oculto ou escondido é o inserido num excesso de gordura suprapúbica (3). Micropênis é aquele que apresenta um comprimento 2,5 desvios-padrão abaixo da média para a idade (4).
Disciplina de Endocrinologia da Fundação Faculdade Federal de Ciências Médicas / Santa Casa de Misericórdia de Porto Alegre, RS.
Recebido em 13/12/99

Revisado em 30/03/00

Aceito em 28/04/00 
Um pênis que não satisfaz os critérios para pênis oculto ou micropênis e tem comprimento inferior ao $10^{\circ}$ percentil para a idade é considerado um pênis pequeno. $\mathrm{O}$ estabelecimento do $10^{\circ} \mathrm{P}$ como valor limítrofe prende-se ao gráfico original de Schonfeld que construiu as curvas com base nos percentis 50, 90 e 10 (5).

São escassos os estudos sobre patogênese, avaliação e evolução dos pacientes com pênis de comprimento reduzido para a idade. Esta entidade se constitui em queixa relativamente freqüente para endocrinologistas e pediatras e está associada, conforme a idade de apresentação do paciente, a angústias dos familiares e/ou do próprio paciente. O objetivo deste estudo foi relatar a avaliação inicial e o seguimento clínico de um grupo de meninos que se apresentaram em idade peri-puberal com a queixa de pênis pequeno.

\section{PACIENTES E MÉTODOS}

Fazem parte da amostra 8 meninos com idade peripuberal, que consultaram com a queixa de pênis pequeno em ambulatório de Endocrinologia da Santa Casa de Misericórdia de Porto Alegre, no período 1994-1999.

Os pacientes foram submetidos a anamnese, exame físico e, em alguns casos, avaliação hormonal que incluiu a dosagem de testosterona $(n=3)$ e $\mathrm{LH}$ e FSH $(n=4)$. O índice de massa corporal (IMC) foi calculado dividindo o peso pela altura ao quadrado, considerando-se como obesidade um indice superior a 30 (6). O pênis foi medido em seu comprimento esticado do púbis até o final da glande, e o respectivo percentil avaliado através da curva de Schonfeld (5). Para quantificar o déficit de comprimento peniano, estabeleceuse o número de desvios-padrão de comprimento conforme a idade, segundo os valores propostos por Hung (7). Os testículos foram medidos com o orquidômetro de Prader. O estadiamento puberal foi feito segundo Tanner (8). A testosterona e as gonadotrofinas foram dosadas através de kits comerciais, respectivamente por radioimunoensaio e quimioluminescência. A idade óssea foi interpretada segundo Greulich e Pyle (9).

\section{RESULTADOS}

\section{Avaliação clínica inicial}

Os meninos se apresentaram com idade entre 10 anos e 9 meses e 14 anos e um mês. A primeira consulta foi motivada em 4 casos por pênis pequeno, em dois por pênis pequeno e obesidade e, nos restantes, por pênis pequeno e atraso puberal. Em todos os casos a altura se encontrava entre o 25 e o 90 percentil, com exceção de um, com altura abaixo do terceiro percentil. Este paciente, com 11 anos e três meses, apresentava idade-altura de 8 anos e 6 meses. O IMC variou entre 17 e 33 , em apenas um caso compativel com obesidade. $\mathrm{O}$ comprimento do pênis variou entre 2,5 e $4,5 \mathrm{~cm}$, em todos os casos abaixo do $10^{\circ}$ percentil. Em 4 casos a medida se situava um desviopadrão abaixo da média e, nos demais, dois desviospadrão. $O$ volume testicular era pré-puberal em todos os casos, oscilando entre 1,5 e $3,5 \mathrm{~cm}^{3}$. O estadiamento dos pêlos pubianos era $\mathrm{P} 1$ em 5 casos e P2 em 3. Idade, IMC, comprimento do pênis e número de desvios-padrão do mesmo em relação à média constam na tabela.

Ao exame físico, um dos pacientes apresentava face redonda e pescoço curto, e outro apresentava fácies sindrômica (com leve micrognatia, hipoplasia do osso malar, aumento da distância naso-labial), pálato em ogiva, cabelo em espiraledo, hipertelorismo mamário, cúbito valgo, escoliose dextro-côncava, manchas café-com-leite, coxa vara e assimetria de comprimento dos membros inferiores.

Os níveis de testosterona total eram prépuberais nos casos avaliados e os de LH e FSH encontravam-se em valores inferiores aos da faixa de referência para adultos. Nos 5 casos em que foi avaliada, a idade óssea foi compatível com a idade cronológica.

Tabela. Idade, IMC, comprimento do pênis e número de desvios-padrão do comprimento do pênis.

\begin{tabular}{|c|c|c|c|c|c|c|c|c|}
\hline Caso & Idade l & $\mathrm{IMCl}^{\mathbf{M}}$ & Pênis $(\mathrm{cm})^{1}$ & No DPI & Idade $^{2}$ & $\mathrm{IMC}^{2}$ & Pênis $(\mathrm{cm})^{2}$ & $N^{\circ} D^{2} 2$ \\
\hline 1 & $13 a 3 m$ & 30 & 3,5 & -1 & $17 a 2 m$ & 39,5 & 7 & -1 \\
\hline 2 & $10 \mathrm{a} 11 \mathrm{~m}$ & 21 & 3,5 & -2 & $13 a 11 \mathrm{~m}$ & 22 & 6 & 0 \\
\hline 3 & $10 \mathrm{a} 11 \mathrm{~m}$ & 21 & 3,5 & -2 & $13 a 11 \mathrm{~m}$ & 20 & 6 & 0 \\
\hline $4^{*}$ & $14 \mathrm{a} 1 \mathrm{~m}$ & 23 & 3.5 & -2 & $16 \mathrm{a} 7 \mathrm{~m}$ & 24 & 6 & -1 \\
\hline $5^{\star}$ & $12 \mathrm{a} 7 \mathrm{~m}$ & 30 & 4 & -1 & - & - & - & - \\
\hline 6 & $13 a 9 m$ & 20 & 3 & -1 & - & - & - & - \\
\hline 7 & $11 \mathrm{a} 3 \mathrm{~m}$ & 17 & 2,5 & -2 & $12 \mathrm{a} 5 \mathrm{~m}$ & 18 & 6 & 0 \\
\hline 8 & $10 \mathrm{a} 9 \mathrm{~m}$ & 33 & 4,5 & -1 & $19 \mathrm{a} 4 \mathrm{~m}$ & 23 & 9,5 & -1 \\
\hline
\end{tabular}

1Na apresentação; 2 Na última avaliação

*Pacientes que fizeram uso de testosterona exógena 


\section{Seguimento}

Em dois casos, o seguimento dos pacientes foi inferior a um ano, sendo os mesmos excluídos das observações sobre acompanhamento; nos demais, o seguimento variou de 1 ano e dois meses a 8 anos e 7 meses (média de 44 meses). A idade na última avaliação variou de 12 anos e 5 meses a 19 anos e 4 meses.

Dois dos pacientes (casos 4 e 5 da tabela) receberam testosterona injetável, $50 \mathrm{mg}$ intra-muscular, uma vez por mês por três meses, seguida num dos casos (caso 4) por três aplicações de $100 \mathrm{mg} /$ mês, três meses. A justificativa para esta decisão terapêutica foi o sofrimento emocional apresentado pelos dois pacientes, um deles com a idade mais elevada do grupo, e o outro pelo impacto visual negativo do reduzido comprimento peniano sobreposto ao excesso de peso.

$\mathrm{Na}$ última avaliação apenas um dos pacientes apresentava IMC compatível com obesidade $(39,5)$. Em todos os casos, o desenvolvimento genital era igual ou maior que G3. O comprimento peniano variava entre 6 e $9,5 \mathrm{~cm}$. Em dois casos o comprimento peniano manteve-se um desvio padrão negativo; em um caso o déficit foi reduzido de -2 para - 1 DP e, nos três casos restantes, que apresentavam comprimento peniano de $-2 \mathrm{DP}$, houve adequação do comprimento aos valores normais para idade. Desses, um havia recebido testosterona. Idade, IMC, comprimento do pênis e número de desvios-padrão do mesmo em relação à média, por ocasião da última consulta, constam na tabela.

Embora um dos pacientes que recebeu testosterona exógena tenha sido excluído dos resultados do acompanhamento, em função de ter permanecido em consulta por apenas 4 meses, cabe ressaltar que na última avaliação apresentava estágio puberal P4 e G3.

\section{DISCUSSĀO}

A consulta por pênis pequeno antes da puberdade é freqüente na clínica endócrina. $\mathrm{Na}$ maior parte das vezes, o diagnóstico é de pseudo-pênis pequeno, associado à obesidade (10). Embora a amostra atual inclua um paciente com obesidade e dois com sobrepeso, em todos os casos o comprimento peniano mostrou-se reduzido para a idade.

Em nenhum dos pacientes aqui avaliados foi possível estabelecer diagnóstico de patologia endócrina. Com relação à presença de hipogonadismo hipogonadotrófico, os níveis de gonadotrofinas basais não são suficientes para estabelecer este diagnóstico na faixa etária estudada. Sabe-se que ocorrem diferenças significativas entre os valores pré-puberais basais de gonadotrofinas e os encontrados a partir do estágio 3 da puberdade, ocorrendo, no entanto, sobreposição de valores nos diferentes estágios puberais (11). Por outro lado, o diagnóstico diferencial de hipogonadismo hipogonadotrófico e retardo constitucional do desenvolvimento e puberdade também não pode ser estabelecido antes dos 18 anos de idade pela resposta ao $\mathrm{GnRH}$, razão pela qual esse teste não foi aqui solicitado.

No paciente que apresentava baixa estatura, a idade óssea mostrou-se compativel com a cronológica e a função tireóidea e o teste de resposta do hormônio do crescimento à clonidina foram normais. Esse mesmo paciente apresentava um quadro sindrômico sugestivo de síndrome de Russel-Silver, com base na baixa estatura, assimetria de membros inferiores, micrognatia e presença de manchas café-com-leite (12). Com relação aos genitais, hipospádia é uma alteração ocasionalmente descrita na síndrome, não havendo menção à redução do comprimento peniano.

As poucas informações fornecidas pelos exames subsidiários, o diagnóstico clínico aparentemente negativo para a presença de endocrinopatia e a possibilidade de concomitância de atraso constitucional do desenvolvimento e puberdade em alguns dos casos apresentados aponta para variantes da normalidade. Neste contexto, condutas intervencionistas devem ser avaliadas com cautela. Optou-se pelo acompanhamento dos pacientes, com exceção de dois casos, um com 12 e outro com 14 anos de idade, nos quais foi feita a intervenção com ésteres de testosterona. Nestes casos, bem como nos de micropênis ou atraso puberal, um curso de terapêutica androgênica pode levar o pênis à faixa normal para a idade, o que permite avaliar sua resposta à testosterona, e prever o potencial de resposta puberal. A resposta é obtida com doses de 25 a $50 \mathrm{mg}$ de enantato ou cipionato de testosterona intramuscular, a cada 3-4 semanas, por 3 meses, e suspensa por período similar (13). Se não forem observadas alterações puberais, especialmente quanto ao tamanho testicular, é feito um curso adicional de tratamento.

Em humanos, o número de receptores androgênicos do pênis normal aumenta na puberdade e diminui na idade adulta, variação essa também apresentada pela enzima 5-alfa-redutase (14). Estudos em ratos sugerem que a exposição precoce à testosterona (15) ou à di-hidro-testosterona (16) acelera a perda de receptores androgênicos, comprometendo o crescimento do pênis. Este dado não foi posteriormente confirmado, nem em ratos (1) nem em humanos, uma vez que Baskin e cols., transplantando pênis fetais humanos em ratos e camundongos, aos quais foram administrados doses altas de ésteres de testosterona (2), não observaram diferença no número de recep- 
tores de andrógenos entre receptores castrados, normais ou tratados com o hormônio.

Assim, num contexto de ausência de alterações induzidas no receptor androgênico, e na ausência de efeitos negativos sobre o potencial de crescimento somático (10) ou posterior função testicular, alterações no comprimento e diâmetro penianos induzidas pela testosterona, mesmo pequenas, podem ser benéficas, tanto do ponto de vista diagnóstico como emocional. Concluindo, a evolução aqui observada aponta para a adoção de conduta expectante até o desencadeamento espontâneo da puberdade, a menos que dificuldades acentuadas do ponto de vista psicológico apresentadas pelo paciente gerem a necessidade de acelerar esse processo.

\section{REFERÊNCIAS}

1. Levy JB, Seay TM, Tindall DJ, Hussmann DA. The effects of androgen administration on phallic androgen receptor expression. J Urol 1996; 156(2S)Supplement::775-9.

2. Baskin LS, Sutherland RS, DiSandro MJ, Hayward SW, Lipshutz J, Cunha GR. The effect of testosterone on androgen receptors and human penile growth. J Urol 1997; 158:1113-8.

3. Crawford BS. Buried penis. Br J Plast Surg 1977;30:96-9.

4. Lee PA, Mazur P, Danish R, Amrhein J, Blizzard RM, Money J, et al. Micropenis: criteria, etiologles and classification. Johns Hopkins Med J 1980; 146:156-63.

5. Shonfeld WA. Primary and secondary sexual characteristics. Am Dis Child 1943;65:535-49.

6. Himes JH, Dietz WH. Guidelines for overweight in adolescent preventive services: recommendations from an expert committee. Am J Clin Nutr 1994;59:307-16.

7. Hung W, Micropenis, hypospadias, and criptorchidism in infancy and childhood. In: Becker KL, editor. Principles and Practice of Endocrinology and Metabolism. Philadelphia:JB Lippincott, 1995:843-50.
8. Tanner JM. Whitehouse RH. Clinical longitudinal standards for height, weight, height velocity, weight velocity and the stages of puberty. Arch Dis Chil 1976;51:170-90.

9. Greulich WW. Pyle SJ. Radiographic atlas of skeletal development of the hand and wrist. 2nd ed. California:Stanford University Press, 1974.

10. Burstein S, Grumbach MM, Kaplan SL. Early determination of androgen responsiveness is important in the management of microphallus. Lancef 1979;2:983-6.

11. Oliveira MC, Camargo Neto E, Pizarro CB, Messinger HP, Tannhauser M. Valores basais de LH e FSH em crianças e adolescentes normais determinados através do método da quimioluminescência. Arq Bras Endocrinol Metab 1996:40:198-202.

12. Jones KL. Smith's Recognizable Patterns of Human Malformation. 15th ed. Philadelphia: WB Saunders Co, 1997.

13. Kulin HE. Delayed puberty in boys. In: Bardin CW, ed. Current Therapy in Endocrinology and Metabolism. 6th ed. St Louis:Mosby, 1997

14. Roehrborn CG, Lange JL, George FW, Wilson JD. Changes in amount and intracellular distribution of androgen receptor in human foreskin as a function of age. J Clin Invest 1987:79:44-7.

15. McMahon, Kramer AS, Hussmann DA. Micropenis: does early treatment with testosterone do more harm than good? J Urol 1995; 154:825-9.

16. Hussmann DA, Cain MP. Microphallus: eventual phallic size is dependent on the timing of androgen administration. J Urol 1994:152:734-9.

\section{Endereço para correspondência:}

Miriam da Costa Oliveira

Rua Dona Mimi Moro 40

90.480-050 Porto Alegre, RS

Fax: (051) 328-6761

e.mail: mco@portoweb.com.br 